\title{
THE CONVENTION ON THE RIGHTS OF PERSONS WITH DISABILITIES (CRPD) AND QATAR'S DOMESTIC LEGISLATION: THE POTENTIAL IMPACT ON THE MAIN LEGAL DOMAINS ${ }^{1}$
}

\author{
PABLO RODRÍGUEZ DEL POZO ${ }^{2}$ \\ MARÍA DEL CARMEN BARRANCO AVILÉS ${ }^{3}$ \\ PATRICIA CUENCA GÓMEZ ${ }^{4}$ \\ KHALID AL ALI ${ }^{5}$ \\ JAVIER ANSUÁTEGUI ROIG ${ }^{6}$ \\ RAFAEL DE ASÍS ROIG ${ }^{7}$
}

\begin{abstract}
Equal rights for persons with disabilities is the ultimate goal mandated by the CRPD, and it can probably be gradually achieved in Qatar as steps are taken towards reconsidering the approach to disability at large. This paper examines what impact the CRPD has on the country's legislation. To that end, we explore how the sensitive domains -health, education, employment, and justice- need to be re-evaluated in light of the CRPD, where recent improvements in the rights of persons with disabilities in Qatar can enable compliance and where the greater challenges lie. We maintain that although legal reforms are needed for Qatar to comply with CRPD, within existing legislation there is notable potential to accommodate particular amendments that could significantly assist the move towards CRPD compliance. We suggest some structural steps aimed at improving compliance, consisting of the establishment of specific institutions, the promotion of associations that represent persons with disabilities and, above all, advancement of a fundamental shift in the way disability is perceived by society, moving away from the old medical notion of disability with its focus on special features and rehabilitation and instead adopting the social model that mandates inclusion and equality.
\end{abstract}

Keywords: Disability, Qatar, Human Rights, United Nations.

Summary: 1. INTRODUCTION 1.1. Disability in Qatar: General framework 1.2. Key concepts in the incorporation of the CRPD model into Qatari legislation 2. CRPD-SENSITIVE AREAS 2.1. Preliminary clarification 2.2. Private law 2.3. Health 2.4. Education 2.5. Labor and employment 2.6. Access to justice 2.7. Participation 2.8. Audiovisual accessibility 3. CONCLUSIONS.

\footnotetext{
1 This publication was made possible by the NPRP award NPRP-7-380-5-051 from the Qatar National Research Fund (a member of The Qatar Foundation). The statements made herein are solely the responsibility of the authors.

${ }^{2}$ Weill Cornell Medical College in Qatar (prd2002@qatar-med.cornell.edu).

${ }^{3}$ Universidad Carlos III de Madrid, Spain (mcarmen.barranco@uc3m.es).

${ }^{4}$ Universidad Carlos III de Madrid, Spain (patricia.cuenca@uc3m.es).

${ }^{5}$ Qatar University (kalali@qu.edu.qa).

${ }^{6}$ Universidad Carlos III de Madrid, Spain (javofil@der-pu.uc3m.es).

${ }^{7}$ Universidad Carlos III de Madrid, Spain (rafael.asis@uc3m.es).
} 


\section{INTRODUCTION}

Qatar is an independent, sovereign state about 11.5 thousand square kilometers in size, located on the western coast of the Arabian Gulf. It has a population of approximately 2.6 million, of which only one in three persons are women (April 2016) ${ }^{8}$; only about 12 percent of the population is Qatari (Snoj 2013)

The Qatari Constitution, adopted on June 8, 2004, recognizes Shari'a law as its main source of legislation. The political system is a monarchy, and the head of state is the Emir, who holds executive power and organizes the Council of Ministers. Legislative authority is vested in the Al-Shoura Council, an advisory body that consists of forty-five members, thirty of whom are elected by direct vote in general elections and fifteen of whom are appointed directly by the Emir.

Qatar has embarked on an ambitious modernization drive, encapsulated in the Qatar National Vision 2030, a policy framework aimed "towards Qatar becoming an advanced society capable of sustainable development with the goal of providing a high standard of living for all citizens” by the year $2030^{9}$. As part of its reform strategy, Qatar, in 2008, ratified the International Convention on the Rights of Persons with Disabilities (CRPD) ${ }^{10}$. In September 2015, Qatar completed its initial review process before the Committee on the Rights of Persons with Disabilities, the UN organization in charge of monitoring the State Parties' compliance with the CRPD ${ }^{11}$.

In a previous paper, we have identified the main opportunities and challenges that implementation of the CRPD entail for Qatar. This current paper aims to present the main legislative domains of Qatari domestic law that the CRPD will impact.

In order to better address the contextual elements that might influence the pace and priorities when implementing the CRPD in Qatar, it is important to highlight some key elements of the CRPD: the international requirements to consider in its implementation, and some observations about the general legal status of disability in Qatar.

\footnotetext{
${ }^{8}$ Ministry of Development Planning and Statistics, Qatar. National Statistics, Population Chapter 2015. Available at http://www.mdps.gov.qa/en/statistics1/pages/topicslisting.aspx?parent=Population\&child=Population (last accessed February 12, 2017).

${ }^{9}$ General Secretariat for Development Planning, Qatar National Vision 2030. Available at http://www.mdps.gov.qa/en/qnv/Documents/QNV2030_English_v2.pdf (last accessed March 29, 2017)

${ }^{10}$ General Secretariat for Development Planning, Qatar National Vision 2030. Available at http://www.mdps.gov.qa/en/qnv/Documents/QNV2030_English_v2.pdf (last accessed March 29, 2017)

${ }^{11}$ However Qatar did not ratify the Optional Protocol of the CRPD regarding the individual complaints procedure and inquiry procedure.
} 


\subsection{Disability in Qatar: General framework}

While most countries include declarations of the rights of citizens in their constitutions, specific references to disability are often absent in constitutional texts, and Qatar is no exception. This omission can be seen as an expression of the historical invisibility of the disabled, and we know now that an express constitutional mention of the rights of persons with disabilities, as is the case with other groups with a history of vulnerability, would be desirable.

The constitutions of some Middle Eastern countries mention the rights of persons with disabilities. Saudi Arabia's Basic Law of Governance of 1992 states in Article 27 that the "state guarantees the rights of the citizen and his family in cases of emergency, illness and disability, and in old age; it supports the system of social security and encourages institutions and individuals to contribute in acts of charity." We can also find references to disability in Article 81 of the Egyptian Constitution of 2014, in Article 48 of the Tunisian Constitution of 2014, in Article 32 of the Iraqi Constitution of 2005, and in Article 12 of the Basic Law of the Sultanate of Oman of 1996. Qatar, together with Mauritania, Morocco, Algeria, Lebanon, Jordan, and Turkey, do not have explicit references to disability in their constitutions.

Article 34 of the Qatari Constitution establishes the equality of rights for citizens, and Article 35 prohibits discrimination based on race, gender, language, or religion. Disability, however, is not explicitly mentioned, and the Constitution has no other specific provision regarding persons with disabilities that would contribute to their visibility before the law.

But while the Constitution itself makes no mention of disability, a national law approved in 2004 -Law 2/2004 on Persons with Special Needs- specifically safeguards persons with disabilities in Qatar. This instrument, in its first article, defines a person with disability as "any person with a permanent total or partial disability in any of the senses or in his or her physical ability or in his or her psychological or mental ability to such an extent that his or her opportunity to learn or to undergo rehabilitation or to earn a living is limited."

Although this law is a robust step forward for the rights of persons with disabilities, the definition is rooted in a purely medical concept of disability, with no mention of the social factors that contribute to the very notion of disability, as mandated by the CRPD. The law limits its protection only to learning, rehabilitation, and livelihood, and does not expressly mention social opportunities. The medical perspective pervades other definitions, such as special education, rehabilitation, and special education institutes. Disability is quite consistently understood, in this legal framework, to be a medical situation related to special features of the persons, and the interventions promoted by the law are oriented towards rehabilitation rather than to social inclusion. 
It is noteworthy that the medical model remains dominant in the 2004 law that guarantees the right to 1) education and rehabilitation; 2) medical, psychological, cultural, and social care; 3) the tools, devices, means of transport, and equipment that assist in learning, rehabilitation, and enjoying freedom of movement; 4) relief, aid, and other ancillary services; 5) employment that is appropriate to their abilities and rehabilitates them in both the public and private sectors; 6) participation in sports and entertainments according to their special abilities; 7) accommodation for safe and secure movement; 8) securing special facilities in public places; and 9) securing their participation in decisions related to their affairs.

Article 3 of the law reaffirms its basis on the medical model of disability, when it orders the agency in charge to 1) ensure medical and psychological services and medical reports to the person with special needs and to his or her caretakers; 2) ensure employment opportunities and rehabilitation according to the individual's abilities; 3) educate the public on the rights of persons with special needs on how to provide aid and support, and to show respect and consideration towards them, including giving support and allowing their integration into society; 4) provide appropriate programs for their education and rehabilitation and to form technical cadres to provide such services; and 5) provide special services in the fields of care, relief, vocational training, family services, technology, sports, and entertainment.

Along the same medical model lines, it should be highlighted that Law 2/2004 stresses the special nature of persons with disabilities, rather than looking for standardization. As noted previously, the Qatari legislation stemming from the Committee on the Rights of Persons with Disabilities recognizes rights with the goal of protecting through special treatment, rather than consecrating equal rights ${ }^{12}$. We will further address this legal text below in the sections dedicated to specific fields.

\section{legislation \\ 1.2. Key concepts in the incorporation of the CRPD model into Qatari}

The incorporation of both the social model and the philosophy of the CRPD require an understanding of some key concepts that must be projected onto the legal system, such as the notions of disability and persons with disabilities, universal design, reasonable accommodation, independent living, and discrimination.

Delving into the meaning of these concepts is a good starting point for assessing the degree of legal implementation of the CRPD.

\footnotetext{
${ }^{12}$ UN Committee on the Rights of Persons with Disabilities, Concluding Observations on the Initial Report of Qatar, CRPD/C/QAT/CO/1, para. 7. Available at

http://tbinternet.ohchr.org/_layouts/treatybodyexternal/Download.aspx?symbolno=CRPD\%2fC\%2fQAT\%2f

CO\%2f1\&Lang=en (last accessed January 10, 2017).
} 
The concept of disability is the main aspect in which the social model is projected ${ }^{13}$. The preamble of the CRPD defines disability as the result of "the interaction between persons with impairments and attitudinal and environmental barriers that hinder their full and effective participation in society on an equal basis with others." The text of the international treaty does not distinguish between different kinds of disability, but some statistics show that persons with intellectual or psychosocial conditions are more likely to be subject to exclusion. Meanwhile, Qatari legislation avoids an explicit general concept of disability ${ }^{14}$, but disability is implicitly conceived as a medical impairment, as in the previously cited Article 2 of Law 2/2004.

Article 9 of the CRPD defines accessibility for persons with disabilities as the "access, on an equal basis with others, to the physical environment, to transportation, to information and communications, including information and communications technologies and systems, and to other facilities and services open or provided to the public, both in urban and in rural areas." The areas of accessibility are "a) buildings, roads, transportation and other indoor and outdoor facilities, including schools, housing, medical facilities, and workplaces; b) information, communications, and other services, including electronic services and emergency services.” Qatari law does not include a general definition of accessibility and lacks a comprehensive accessibility plan, despite the existence of specific regulations on accessibility in some areas.

Universal design is defined by Article 2 of the CRPD as "the design of products, environments, programs, and services to be usable by all people, to the greatest extent possible, without the need for adaptation or specialized design.” It further states that "universal design shall not exclude assistive devices for particular groups of persons with disabilities where this is needed." Universal design is the tool to achieve universal access. There is no mention of it in the current legal framework for persons with disabilities in Qatar.

The CRPD's Article 2 considers reasonable accommodation as the "necessary and appropriate modification and adjustments not imposing a disproportionate or undue burden, where needed in a particular case, to ensure to persons with disabilities the enjoyment or exercise on an equal basis with others of all human rights and fundamental freedoms." When universal design is not enough to guarantee universal accessibility, reasonable accommodations are required. Qatari legislation has not yet developed a notion of reasonable accommodation, which is in accordance with the medical model of disability. In this framework, the general idea underlying the treatment of disability is that there are

\footnotetext{
${ }^{13}$ For a further explanation of the social model and its implication for Qatar, see Rodríguez del Pozo P., Barranco Avilés M.C., Cuenca Gómez P., Al Ali K., de Asís Roig R., “The Impact of the International Convention on the Rights of Persons with Disabilities on Qatari Domestic Legislation”. The Age of Human Rights Journal, 2017 (in press).

${ }^{14}$ Other terms related to persons with disabilities are defined in several legal documents, as we will see, but the language is inconsistent with the requirements of the CRPD.
} 
persons who need to be adapted to the environment. The social model proposed by the CRPD, conversely, maintains that the environment needs to be adapted to the persons.

With respect to independent living, the CRPD, in Article 19, affirms that "States Parties to this Convention recognize the equal right of all persons with disabilities to live in the community, with choices equal to others [...] ensuring that: (a) persons with disabilities have the opportunity to choose their place of residence and where and with whom they live [...]; (b) persons with disabilities have access to a range of in-home, residential, and other community support services [...] to prevent isolation or segregation [...]; (c) community services and facilities for the general population are available on an equal basis to persons with disabilities [...]." We have not found in Qatari legislation any passages that could be invoked to support this notion of independent living.

Article 5 of the Convention refers to equality and non-discrimination, recognizing that all persons are equal before the law and mandating that States Parties "prohibit all discrimination on the basis of disability and to guarantee to persons with disabilities equal and effective legal protection against discrimination on all grounds.”

Discrimination on the basis of disability means any distinction, exclusion, or restriction on the basis of disability that has "the purpose or effect of impairing or nullifying the recognition, enjoyment or exercise, on an equal basis with others, of all human rights and fundamental freedoms in the political, economic, social, cultural, civil or any other field” (Article 2 CRPD). The CRPD concept of non-discrimination recognizes that the denial of reasonable accommodation is a form of discrimination.

Since the Constitution of Qatar does not grant explicit protection against discrimination for persons with disabilities and since Qatari legislation is based on the medical model of disability and does not incorporate the key concepts of the CRPD ${ }^{15}$, both Constitution and legislation require an overhaul to become fully CRPD-compliant. However, until these reforms are undertaken, State Parties can find other effective ways to build strong legal protection for persons with disabilities.

As comparative law shows, even if the legislative corpus of a country predates the Convention, national legislation can be reinterpreted in its wake, and the jurist will find a number of traditional legal institutions that, under this new interpretation, are applicable as positive law for the protection of persons with disabilities in the terms defined by the CRPD. For example, Articles 34 and 35 of the Qatari Constitution explicitly forbid discrimination. Although they do not refer specifically to disability, we believe that the courts have ample room to interpret constitutional protection in a way that grants an equal basis to persons with disabilities due to Qatar's ratification of the Convention.

\footnotetext{
${ }^{15}$ See Concluding Observations, CRPD/C/QAT/CO/1, paras 11, 19, 37.
} 
In the following sections, we will analyze different areas that are particularly significant when guaranteeing persons with disabilities the same level of protection of their rights as that granted by the CRPD. We understand that such protection should include the corresponding legal actions to make those rights effective. We will analyze in each case whether a CRPD-compliant protection, under the current CRPD interpretation, is guaranteed, from a strictly textual point of view, by Qatari legislation. We will present a basic description of the most critical, termed "sensitive", areas in the protection of the rights of persons with disabilities, aimed at understanding later our assessment of Qatari law from the point of view of the CRPD. If we find that Qatari legislation is not clear, we will propose the most parsimonious legislative alternative to achieve that goal through interpretative alternatives. When that approach seems technically difficult, we will suggest the need for further practical legislative reform.

Indeed, the analysis of Qatari legislation will take into consideration a number of policy areas corresponding to different topics. The division in these areas is the result of the interaction of five main arguments: inclusion, the fabric of the CRPD, other countries' experiences in the implementation of the CRPD, conclusions on the current situation in Qatar reached in other stages of the present research, and the particular features of this paper.

\section{CRPD-SENSITIVE AREAS}

\subsection{Preliminary clarification}

Before analyzing the areas most sensitive to the implementation of the CRPD, we need to clarify that this analysis is without prejudice to other obligations that the CRPD lays down for States Parties, such as duties related to awareness-raising, to institutional organization to monitor CRPD implementation, and to statistics and data collection. In these areas, Qatar has made very successful strides towards compliance.

Awareness programs have been carried out by the Department of Elderly and Disabled Persons in the Ministry of Social Affairs through television advertisements in which the rights of people with disabilities are explained; through programs run by the Social and Cultural Center for [the] Deaf; through Al-Noor Institute bulletins; and through the Shafallah Center for Children with Special Needs' campaigns dedicated to Down's syndrome and autism. These efforts have been remarkably successful. Further synergy and, thus, greater effectiveness and efficiency, would be gained if these relatively isolated actions became more systematic. Conventional wisdom dictates that it would be desirable to draw up a general plan of sensitization and awareness under the supervision of an agency that coordinates the different strategies and actions, and that can monitor them under a single, coordinated strategy. However, it is beyond the scope of this study to measure the effectiveness, let alone the efficiency, of the systemic versus the single-institution approach. 
Qatar has created institutions that, in one way or another, are in charge of the institutional monitoring of CRPD implementation, such as the Shafallah Center for Children with Special Needs (2001), the Cultural Center of Mother and Child (2003), the Family Guidance Center (2003), the Qatar Foundation for the Protection of Children and Women (2003), the Qatar Foundation for the Care of Orphans (2003), the Qatar Foundation Against Trafficking in Persons (2005), the Center for Social Rehabilitation (2007), and the Qatar Foundation for the Care of Older Persons (2003). The Supreme Council for Family Affairs -now the Department of Family Affairs at the Ministry of Administrative Development, Labor and Social Affairs- was the government agency in charge of CRPD implementation until 2015. While the National Human Rights Commission has competencies in monitoring the situation of people with disabilities and has conducted fieldwork on the matter, there is no single body aimed at directing and coordinating disability policy. Nevertheless, the foundation of these various individual organizations is significant and shows a government-wide commitment to secure the rights of persons with disabilities and the implementation of the CRPD. Given the number of institutions and agencies sharing similar tasks, the question emerges as to whether there are possible overlaps, duplication of tasks, and misunderstandings amongst institutions. Though this assessment is beyond the remit of the present study, the existence of a single agency in charge of distributing roles and assigning tasks to the various institutions would make working towards the implementation and monitoring of the CRPD more efficient.

Finally, Qatar has taken several steps towards filling the gaps, as discussed earlier, in relation to its obligations on statistics and data collection regarding disability ${ }^{16}$. It is worth mentioning the Global Survey on Persons with Disabilities (developed in collaboration with the Supreme Council for Family Affairs), the Qatari National Institute of Statistics survey, and monographic chapters devoted to persons with disabilities, published in the government's national annual statistical report. Important steps have been taken to improve the capture and collection of data, broken down by disability-type, exploring the situation of persons with disabilities. It is also important that information is not simply reduced to numerical indicators, and that confidentiality and respect for the privacy of persons with disabilities are ensured throughout the process. Thanks to these efforts, Qatar now has a reliable statistical system, which is critical for an adequate decision-making process.

In the following pages, we will analyze legal texts in the light of the CRPD, in legislative areas that are most critical from the standpoint of the human rights doctrine.

\footnotetext{
${ }^{16}$ In its Concluding Observations on Qatar, the Committee on the Rights on Persons with Disabilities "welcomes the inclusion of questions on disability in the 2010 population census, as a first effort to understand the situation of persons with disabilities.” Ibid., CRPD/C/QAT/CO/1, para. 4.
} 


\subsection{Private law}

Legal capacity, which is the legal right to engage freely in contracts that may result in legal obligations and to exercise rights as an independent individual, has historically been approached from the perspective of the medical model of disability by civil laws around the world. In this paradigm, persons with disabilities, most particularly persons with psychosocial or intellectual disabilities, are conceived as persons incapable of making decisions due to their impairments. Hence, in order to protect the best interest of the persons with disabilities, the power to make legally binding decisions needs be stripped from them and given to a legal guardian who will act on their behalf.

Legal theory considers capacity to be a technical (Quinn 2009) tool aimed at protecting legal security. The removal of legal capacity and its substitution with a guardianship system carries, for psychosocial or intellectually disabled people, the withdrawal of their control over their property and financial affairs, so that they are guarded against their own unwise decisions or those made potentially abusively by third parties. However, the denial of legal capacity due to psychosocial or intellectual disability effectively compromises the civil and fundamental rights of persons with disabilities. For instance, persons with psychosocial or intellectual disability, once deprived of legal capacity, do not have the choice to decide when they wish to move and with whom they wish to live, and cannot initiate legal action on their own to protect their dignity in the case of alleged abuse.

The CRPD is a paradigm shift in the field of legal capacity. The Convention considers legal capacity as a human rights issue, which means that it is of critical value to ensure effective exercise of civil, political, economic, social, and cultural rights, and requires treatment of the individual according to the values that animate human rights (dignity, autonomy, liberty to make one's own decisions, and equality) ${ }^{17}$. The regulation of legal capacity should similarly be undertaken in accordance with the Convention's social model of disability.

The adoption of the social model involves understanding that the problems that some people may encounter when making decisions are related not so much to their own personal characteristics, but rather to social factors. Thus, the point of departure should be to recognize the full legal capacity of all persons with disabilities, and to provide persons with disabilities the choice to receive support in situations when they have difficulties in making decisions or communicating them to others, in accordance with their own will and preferences. National legislation should, in the CRPD's paradigm, move from a model of substituted decision-making towards assisted decision-making.

\footnotetext{
${ }^{17}$ This approach is clear in the position of the Committee on the Rights of Persons with Disabilities, General Comment No. 1, "Equal recognition before the law,” adopted April 11, 2014, CRPD/C/GC/1. Concluding Observations.
} 
In Qatari legislation, as in most national laws today, such a paradigm shift has not yet been adopted. In Qatar, persons with psychosocial and intellectual disabilities may be deprived of their legal capacity and be put under guardianship. At the same time, under Qatari law, the exercise of some fundamental rights requires being sound of mind.

In Qatar, personality is considered a universal trait, attributed to all human beings in its Civil Code, and there are no restrictions or gradations on the basis of disability ${ }^{18}$. However, Qatari legislation is rooted in the substitution model with regards to legal capacity. The Civil Code determines that the recognition of full legal capacity depends on full legal age, which is reached at the age of 18, and on "mental competence". In this regard, those who are not considered mentally competent may be incapacitated.

Incapacitation in Qatari legislation can be total or partial (as determined by Articles 49 and 52 of the Civil Code and Article 190 of the Family Code). Legally incapacitated persons are subjected to a system of guardianship (curation or qawama) in which a third person takes care of and represents the person and administers his or her property in accordance with the provisions of the law (Article 40 of the Law on the Guardianship over Minors Funds). Regarding incapacitation procedures, Qatari law requires a judicial decision (Article 118 of the Civil Code and Article 33 of the Law on the Guardianship over Minors Funds). Qatari legislation does not include any references to the obligation to take the person's own will and preferences into account during the incapacitation procedure or during the application of the system of guardianship. Specific institutions are given the legal competence to monitor the guardianship system.

Although Qatar's legislation is based on the substitution model, some of its provisions seem to provide mechanisms that allow incapacitated persons to manage their assets. Article 34 of the Law on the Guardianship over Minors' Funds establishes that some persons under guardianship may take over the management of all or some of their assets, with the permission of a judge and after the office of the general attorney has been consulted. In this case, the provisions on minors authorized to manage their assets applies to persons with disabilities. It is not clearly stated which category of incapacitated persons may use these mechanisms, but the principle is very encouraging from the perspective of the CRPD.

The Civil Code (Articles 119-125) also considers that persons under interdiction for prodigality or for "inattentiveness" may be legally competent to perform certain acts, including the administration of their property, the conclusion of an employment contract or the execution of a will. Insofar as the applicable legislation fails to provide an express definition of the notion of "inattentiveness," it remains unclear to which incapacitated

\footnotetext{
${ }^{18}$ Law [Act] No. 22 of 2004 Promulgating the Civil Code. As pointed out in Article 39 of the Civil Code "the personality of a human being shall commence upon being born alive and shall cease upon death.”
} 
persons with disabilities, if any, these provisions apply. However, the existence of these provisions may be seen as a good step towards the implementation of the CRPD.

Even more encouragingly, Qatar's legislation includes a mechanism to assist some persons with disabilities when concluding a contract. The Civil Code allows people with severe physical and sensory disabilities (particularly deaf and dumb, blind and deaf, or blind and dumb, in the code's words), who "cannot understand the contents or surrounding circumstances of a contract, or cannot effectively communicate his will," the possibility of appointing "a judicial assistant to assist such person as may be necessary in his best interests” (Article 127). These provisions establish a model of assistance or support in the field of contracts that could be extended to all areas and which could also be applied to persons with intellectual or psychosocial disabilities, to replace the models of incapacitation and substitution. However, to fully comply with the Convention, this model should change the "best interest" standard to that of the "best interpretation of the will and preferences" of the person.

The Committee on the Rights of Persons with Disabilities has expressed its concern about substituted decision-making and guardianship regimes for persons with disabilities that restrict the exercise of rights, including the right to vote, to marry, to have a family, to give or withdraw free and informed consent, to access justice, and to choose where and with whom to live. Recalling its General Comment No. 1, the Committee has recommended that Qatar carry out a review of its legislation with a view to repealing regimes of substituted decision-making and replacing them with supported decision-making regimes, which uphold the autonomy, will and preferences of persons with disabilities ${ }^{19}$.

The adaptation of Qatar's legislation to accommodate Article 12 of the CRPD is one of the biggest challenges posed by the Convention, as happens with almost all States Parties, requiring profound legal reform. This reform would be very difficult to deliver in the short term, as the experience of other countries shows. However, there are some provisions in Qatari law that allow incapacitated persons to make their own decisions in some spheres, which provides an advantageous starting point for the implementation of Article 12. Moreover, until legal reform takes place, Qatar could in practice come close to complying with the CRPD by extending the assistance model of Article 127, employing rules of interpretation, to all persons with disabilities and to all domains. A specific rule of interpretation could establish that "best interest" includes primarily the best interpretation of the will and preferences of the person with disabilities. These rules could be implemented through different mechanisms according to Qatar's legal and institutional framework while government and stakeholders are working on more complex legislative reforms.

${ }^{19}$ Concluding Observations. CRPD/C/QAT/CO/1, paras 23 and 24. 


\subsection{Health}

Qatari laws and regulations on disability are rooted in the medical model. Consistent with this, it is interesting to observe from the social model perspective that some issues not related to health are solved through health legislation and regulations or are made dependent upon medical decisions. The prevalence of this health perspective is quite challenging when carrying out research on disability and legislation, because often the instrument that guarantees the rights of persons with disabilities exists, but is difficult to identify because it is, to the objective observer, masked as a medical or rehabilitative regulatory matter. For example, the Supreme Council for Health seems to be the body in charge of raising awareness as required by the CRPD, while public policies on disability are mainly related to health and social assistance.

In spite of the core role of health in the treatment of disability, there seems to be a lack of a common procedure to decide who is a person with disability. In some way, this would be advantageous if the recognition of a person as a "person with disabilities" did not depend on an administrative decision on the basis of medical factors. The problem is, however, that as a result of the lack of coordination among the different bodies managing the rights of persons with disabilities, individuals are separately assessed almost for every service.

Law 2/2004 establishes the rights of "Special Needs persons" to "medical, psychological, cultural, and social care" (Article 2) and states that the Supreme Council for Family Affairs ${ }^{20}$ shall work to ensure the "provision of medical preventive, treatment, health, and psychosocial services and provision of the relevant medical reports to the Special Needs Persons and to persons taking care of them provided that such Special Needs Persons and those taking care of them are not covered by any other health insurance system” (Article 3). Thus, Qatar's main provisions on disability seem aimed to ensure persons with disabilities can access to healthcare without discrimination. A physician determines whether the individual impairment qualifies as a disability, establishing if it is temporary or permanent.

Nevertheless, even if access to healthcare is guaranteed, persons with psychosocial and intellectual disabilities have historically lacked the opportunity to take decisions regarding their health. There are some pre-CRPD pieces of healthcare regulation in Qatar that give the disabled a voice, possibly placing the country at the vanguard of compliance in this field. However, not all regulations are so progressive, as we will see below.

\footnotetext{
20 The Supreme Council for Family Affairs has been phased out and part of its functions have been assumed by the Department of Family Affairs at the Ministry of Administrative Development, Labor and Social Affairs.
} 
Today, Hamad Medical Corporation (HMC), created by Decree No. 35 of 1979 and amended by Decree No. 38 in 1987, is a conglomerate of hospitals and outpatient services that represents Qatar's de facto National Health Service. It provides universal coverage to nationals and residents, and most of its services are available for all on a free or nearly free basis. In the context of the prevailing medical and rehabilitative model of disability in Qatar, HMC's policies and regulations are the obvious places to identify issues related to the right to healthcare within the healthcare system for persons with disabilities.

It is among HMC regulations that we have found a policy on informed consent (CL 7226, September 2014), which states that minors or incompetent patients must act through a legal guardian. Competent patients are, in the policy's definitions, persons over 18, able to understand an illness, able to understand consequences and alternative treatments offered, and able to make and communicate choices. To this end, under the policy on "Patient and Family Bill of Rights and Responsibilities” (CL 7225, rev. January 2005), patients have the right to be informed along with their legal representative or legal guardian, who may be required to be present during the explanation of medical information. This possibility should be understood as a guarantee for persons with disabilities since it can be interpreted as assistance rather than the old-fashioned substitution model.

HMC's policy on informed consent, in turn, mentions a procedure in cases when an interpreter is needed. This protection should be interpreted broadly in order to assist persons with sensorial or mental disabilities (including psychosocial and intellectual disabilities) whose communication problems require the use of special languages such as sign language or other supports. In general it is possible to extend the protection of persons with disabilities by expanding, through interpretation to clinical care, the existing policies of the Qatar Regulations and Guidelines for Research Involving Human Subjects ${ }^{21}$, which consider "handicapped" or "mentally disabled" persons as vulnerable persons. HMC's Policy CL 7221 on the Care of Vulnerable Patient Population only refers explicitly to "patients with emotional or mental illness", but persons with intellectual disabilities may be also included. So, the accommodations provided by this Policy, in our criteria, could be incorporated by use and practice; therefore, although a written interpretative policy would be desirable, we do not consider it absolutely essential. In our view, progressive, CRPDcompliant policies can be applied using existing HMC regulations.

In the specific domain of mental health, significant improvements have taken place in Qatar in the recent years, but there is still a long way to go ${ }^{22}$. The great milestone was

\footnotetext{
${ }^{21}$ Approved by the Qatar Health Research Ethics Committee and edited by the Qatar Supreme Council of Health.

${ }^{22}$ The 2015 Annual Report of the National Human Rights Committee on the Situation of Human Rights in the State of Qatar and the Committee Activities, p. 73 and p. 55, said that "mental disability constitutes the main challenge, as this group is facing the social exclusion" and included some specific observations about mental patient conditions. Available at http://www.nhrc-qa.org/wp-content/uploads/2014/01/93621-National-HumanRights-English.pdf (last accessed January 3, 2017).
} 
the approval of Qatar's National Mental Health Strategy 2013-2018 ${ }^{23}$ (Shar that aims to reform the mental health system in order to achieve two main objectives: to raise public awareness and reduce the stigma associated with mental illness, and to provide the best possible inclusive mental health services for the people. So, the Strategy clearly supported a shift "from the model of patient hospitalized in psychiatric departments to the model of attention in community services"(Sharkey 2017: 18-21). This vision is fully in accordance to the CRPD social model based on the principles of "respect for inherent dignity, individual autonomy including the freedom to make one's own choices, and independence of persons" and "full and effective participation and inclusion in society." 24 HMC has recently launched services for the implementation of the Strategy, ${ }^{25}$ focused on in-home, residential, and community support. The creation of a network of community-based specialized mental health centers and the implementation of the mental health home care is worth mentioning.

According to the Strategy, a mental health law to safeguard the human rights of persons with a mental illness was to be enacted in December 2015. Finally this Law was approved more than a year overdue. The Law 16/2016 on Mental Health gives "psychiatric patients" specific rights (related to being informed about their health condition and their rights; ${ }^{26}$ related to their treatment environment; ${ }^{27}$ related to their medical treatment, ${ }^{28}$ and related to their independence and privacy $^{29}$ ). It also introduces some penalties to avoid abuse or neglect by medical staff.

For the first time, the Law on Mental Health details when a patient in Qatar can be forced to be hospitalized in a mental health institution. ${ }^{30}$ According to the Law, compulsory

\footnotetext{
${ }^{23}$ General Secretariat, Supreme Council of Health, 2013, Qatar's National Mental Health Strategy. Changing Minds, Changing Lives, 2013-2018. Available at http://nhsq.info/app/media/1166 (last accessed March 31, 2017).

${ }^{24}$ According Article 19 of the CRPD, related to the right to live independently and be included in the community.

25 Available at https://www.hamad.qa/EN/hospitals-and-services/Rumailah-Hospital/HospitalServices/Clinical\%20Departments/Pages/Department-of-Psychiatry.aspx (last accessed January 3, 2017).

${ }^{26}$ For example the right to receive an in-depth explanation, in an understandable way, of all rights set out in the law, immediately after being admitted, including the right to file a complaint in accordance with the applicable procedures.

${ }^{27}$ The Law establishes, for example, that the patient's individual rights shall be observed by way of providing a health service and a humanitarian setting that preserves his/her dignity and enables his/her medical and personal rights.

${ }^{28}$ According to the Law, the patient shall access the required treatment according to the widely recognized medical standards, shall be provided with the opportunity to be effectively and continuously involved in the treatment process and shall be consulted in all matters related to his/her treatment.

${ }^{29}$ Including the right to be protected from commercial and sexual exploitation, physical and psychological abuse, and humiliating treatment in any way.

${ }^{30}$ Before the approval of this Law there was a lack of general regulation on forced institutionalization of persons with mental disabilities but this practice seemed exist. Regarding this issue, the UN Committee on the Rights of Persons with Disabilities expressed its concern "about the involuntary detention of persons in
} 
admission shall only be permissible a) in case the deterioration of the health and the psychological condition of a person with a psychiatric disease is probable and imminent b) in case the symptoms of the psychiatric disease represent a serious and imminent danger to the safety and health of the patient and other people. ${ }^{31}$ These provisions, that are very similar to other national legislations and introduce some safeguards, serve as a positive step in comparison with the previous lack of regulation.

However, the UN Committee on the Rights of Persons with Disabilities has made a general clarification in the sense that these kind of provisions allowing involuntary detention of persons with disabilities based on dangerousness, alleged need of care or treatment or other reason tied to mental health diagnosis are contrary to the right to liberty recognized in Article 14 of the CRPD. ${ }^{32}$ Other aspects of the Law on Mental Health, such as the role of legal guardians in the case of legally incompetent patients and the regulation of compulsory psychiatric treatment, may be also problematic from the point of view of the CRPD. ${ }^{33}$

To fully comply with the CRPD, Qatar should adopt measures aimed at ensuring that the legal grounds upon which restriction of liberty of an individual is determined are separated from their disability and that assistance should be offered to persons with psychosocial disability to make their own decisions about medical treatment, including in crisis situations.

specialized institutions on the basis of their impairment as well as the deprivation of liberty based on disability including intellectual and/or psychosocial disabilities.” See Concluding Observations. CRPD/C/QAT/CO/1, para. 27. In any case in the penal field Law 23/2004 Promulgating the Criminal Procedure sets out compulsory detention and institutionalization for persons with disabilities who are suspected of being authors of criminal acts and it also allows that the victims of crime, who have a mental disability, may be placed temporarily in a therapeutic facility. Both aspects are related to access to justice and the Committee also has expressed its concern about them.

${ }^{31}$ Involuntary admission requires the approval of the consultant psychiatrist and notification to be sent to the patient's family or guardian, the director of the treatment institution and also to the competent administrative body within 24 hours of admission. The Law also lays down the circumstances in which patients can be made to remain in the hospital, even if they have admitted themselves voluntarily.

${ }^{32}$ Committee on the Rights of Persons with Disabilities, Guidelines on article 14 of the Convention on the Rights of Persons with Disabilities: the right to liberty and security of persons with disabilities, adopted during the Committee's $14^{\text {th }}$ session, held in September 2015 . Available at http://www.ohchr.org/Documents/HRBodies/CRPD/GC/GuidelinesArticle14.doc (last accessed January 3, 2017). According the Committee, Article 14 in the CRPD prohibits the deprivation of liberty on the basis of actual or perceived impairment "even if additional factors or criteria are also used to justify the deprivation of liberty."

${ }^{33}$ The Law also specifies that electroconvulsive therapy is permitted in Qatar, but only under general anesthesia. 


\subsection{Education}

There are three different models for schooling persons with disabilities: segregation, integration, and inclusion. Inclusive education is key not only for the personal development of those with disabilities but also in order to build a more inclusive society. This model of education demands that learning environments are physically, attitudinally, and methodologically aligned with the universal design for learning. Our impression, from recent discussions with experts and key informants, is that there is ample consensus among educators in Qatar for the need to embrace this model. ${ }^{34}$

Consistently, Qatar seems to be going through a paradigm shift. The government made public that the Supreme Education Council was committed to a new teaching philosophy for children with special needs. Within this policy, "all students deserve the right to participate in all educational experiences" and "the Supreme Education Council believes that whenever possible, special needs students should be taught in a normal classroom setting." 35 Although the language might seem anchored in the "special needs" point of view, the philosophy to which the Qatari government is committed is a major step in the direction promoted by the CRPD. This step, despite the fact that it is focused on integration, will pave the way to move quickly towards the inclusive model. Most countries are still at the integration stage. To reach the point of full inclusion, Qatar will need the new philosophy to percolate down to all agencies and institutions involved in education. The challenge is no small one. In our opinion, shifting towards the new paradigm will require a degree of legislative reform.

Free education until the age of 18 is a constitutional right (Articles 25 and 49) in Qatar. It is mandatory for children to be in school until that age or until they finish secondary school, whichever happens first (Law 25/2001 on Compulsory Education).

Law 2/2004 on Persons with Special Needs includes the rights of persons with special needs to access education and rehabilitation relevant to their developmental potential (Article 2.1). Law 25/2001 on Compulsory Education, in turn, sets out that "Any child who develops an illness or disability that prevents him or her from attending public or private schools is excused from mandatory education for the period of such illness or disability in accordance with a decision from the Minister based on a certificate of a Competent Medical Authority at the Supreme Council of Health. This exemption also applies to any child suspended from school due to temporary circumstances. Exemption

\footnotetext{
34 In March-April 2016, our team held a number of meetings and interviews with experts and key stakeholders on this and other issues related to our research. Please see acknowledgments for further details.

${ }^{35}$ Available at http://portal.www.gov.qa/wps/portal/topics/Education+and+Research/Special+Needs+Education (last accessed January 3, 2017).
} 
from mandatory school attendance shall cease when such illness, disability, or temporary circumstance no longer affects the child” (Article 8).

This text becomes obsolete in the light of the new paradigm embraced by the Qatari educational authorities. It is clear, first, that it follows the medical model of disability, which considers disability a health issue. On the other hand, the new paradigm demands that the educational system adjust to the child's personal disability situation. This means that the state should set up an accessible school system, with adequate supports to guarantee children with disabilities the right to equal education. The now outdated text of Law 25/2001, instead, exempts children with disabilities, or illness, from the compulsory education system. Therefore, the law, instead of including or integrating, actually removes children with disabilities from the mainstream, mandatory educational system. This legal clause should be rewritten in order to represent the actual philosophy adopted by educators and authorities in Qatar, which would, in turn, be consistent with the mandates of the CRPD.

Meanwhile, although somewhat unsystematic, major efforts have been made in the last few years to enable the inclusion of children with physical disabilities in general schooling (Al Attiyah A. and Mian M. 2009: 29). There has not been a similar drive on behalf of the children with intellectual disabilities in Qatar.

In that regard, the UN Committee on the Rights of Persons with Disabilities expressed its concern regarding the steps taken by the country to provide reasonable accommodation to all students with disabilities in mainstream schools. It also commented on the need for an inclusive education strategy, being concerned that only students with certain kinds of impairments attend mainstream education while others are enrolled at separate-which the Committee termed "segregated"-facilities. ${ }^{36}$ The Committee most likely meant that children with disabilities are normally referred to the Shafallah Center for Children with Special Needs, a specialized educational institution for boys and girls with intellectual disabilities. In this otherwise very competent, prestigious institution, children are educated, but not integrated, let alone included, into the mainstream system in the way educators, authorities, and the CRPD unanimously promote.

The 2014 report of the National Human Rights Committee (NHRC), the agency for the protection and promotion of human rights in Qatar, mentions that the Supreme Education Council has assumed the responsibility of integrating "special needs children in independent schools," 37 and that in such capacity, the Council has produced reliable information on programs and budget. However, the NHRC mentions in its report that as of

\footnotetext{
${ }^{36}$ Concluding Observations. CRPD/C/QAT/CO/1, para. 43.

37 “Independent schools” refer to the majority of Qatar's primary and secondary public schools.
} 
then, "there is no accurate information regarding the progress in said programs." 38 Finding that information is beyond the scope of our study. However, a specific pilot project to promote the integration of children with autism in mainstream education has been developed in some areas to the north of the country.

Despite substantial progress being made in Qatar to incorporate people with disabilities into educational spaces, a coordinated program is still required. At the same time, the inclusion of children with intellectual disabilities remains a challenge to be addressed. Additionally, the issue of vocational training, connected to the right to work, is yet to be addressed, although national authorities are developing some initiatives in this field.

\subsection{Labor and employment}

Persons with disabilities have, worldwide, a lower level of activity and employment rates than the rest of the population. Until recently, persons with disabilities were often considered unable to work. When disability started to be seen as a medical issue, most societies implemented rehabilitative measures aimed at repairing the individual's disabilities. This medical model was an advancement from the darker days of marginalization of the disabled.

However, in the social model, disability arises from the interaction between the individual's impairments and social barriers. Thus, the problems a person with disabilities encounters in joining the labor market have to do with socially constructed barriers, either physical, communicational, or attitudinal. We know now that it is the work environment that must be adapted to the person with disability, not the other way around.

Qatar is paving the way for persons with disabilities to enjoy their right to work. However, the approach is based on specialty, and usually persons with disabilities are placed into niche tasks within the range of their perceived ability. Law 2/2004 on Persons with Special Needs considers, as a right, the "provision of work that is appropriate to their abilities and rehabilitates them in both the public and private sectors" (Article 2.5). Furthermore, under this same Law, persons who are unable to work shall be entitled to a monthly pension (Article 9).

The underlying principles of the law are rooted in the medical and rehabilitative model of disability. In this framework, personal abilities, which should be improved by

\footnotetext{
${ }^{38}$ National Human Rights Committee, Report of the National Human Rights Committee (NHRC) on the Situation of Human Rights in the State of Qatar and the Committee's Activities during the Year 2014, p. 48. Available at http://www.nhrc-qa.org/wp-content/uploads/2014/01/en_2014-NHRC-report_finalss2.pdf (last accessed January 3, 2017). The 2015 NHRC Report on the Situation of Human Rights in the State of Qatar, cit., p. 73, stresses the difficulties in access to education for persons with "mental disabilities." The methodology of this report included meetings with persons with disabilities and their families.
} 
rehabilitation, are the condition for work. The CRPD, in contrast, demands that barriers are identified in order to adapt the workplace to make it accessible and reasonably accommodating for persons with disabilities. Under current Qatar law these general and individual adaptations of the work environment are not compulsory, although some specific programs and institutions promote reasonable accommodations. However the scope of these measures is still very narrow.

Law 2/2004 establishes that two percent of job positions in the public sector, and a similar percentage for private companies employing more than 25 workers, must be allotted to persons with disabilities. Consistent with the text of Article 2.5, the right of persons with disabilities is the "provision of work that is appropriate to their abilities and rehabilitates them in both the public and private sectors"; thus there is no mandate in the law to adapt the workplace to persons with disabilities as required by Article 27.1.i of the CRPD. While the quota system could remain unchanged, it is quite clear that Article 2.5 needs to be reworded in order to express the mandates of the Convention. However, in their Report to the Committee on the Rights of Persons with Disabilities, national authorities mentioned that they are considering the abolition of the quota system. ${ }^{39}$

The UN Committee on the Rights of Persons with Disabilities recommended that Qatar "adopt the policies and measures, including affirmative action, to significantly increase the employment rate of persons with disabilities, especially women, in the open labor market in public and private sectors." The Committee also recommended "that the State party adopt measures to develop placement services and continuing training, as well as self-employment and entrepreneurship opportunities." 40

Despite these necessary improvements, there are very valuable elements in the current text of Law 2/2004. Article 7 states that persons with disabilities recruited in accordance with Article 5 "may not be denied or excluded from any privileges or rights prescribed generally for staff employed at the organization for which the [person with] special needs works.” This is an expression of the CRPD's principle of non-discrimination, to be enforced by penalties in case of transgression, as per Article 11 of the same law, even if there seems to be no special procedure for the application of penalties, which would reinforce Article 11's deterrent strength.

\subsection{Access to justice}

The right to access to justice is an autonomous fundamental right, and is also of critical importance to the enjoyment of all other human rights. Such a broad concept encompasses the individual's effective access to the systems, procedures, information, and locations used in the administration of justice. It also includes -in accordance with the

\footnotetext{
${ }^{39}$ Concluding Observations. CRPD/C/QAT/1, para. 205.

${ }^{40}$ Ibid., CRPD/C/QAT/CO/1, para. 50.
} 
CRPD - not only the participation of persons with disabilities as users (i.e. parties or witnesses) in judicial proceedings, but also their contribution to the administration of justice as judges, prosecutors, or other lawyers (Ortoleva 2011: 281-320).

International experience shows that persons with disabilities are all too often denied access to justice on an equal basis with others. They face barriers usually related to the secular medicalization of disability, among them a lack of legal capacity, lack of accessibility and accommodation, and lack of information and awareness of rights and remedies, not to mention financial barriers, stereotyping, and prejudice. ${ }^{41}$

These barriers usually stem from the fact that justice systems are designed for the standard citizen and, despite some provisions, are not sufficiently sensitive to the needs of persons with disabilities. Qatar, to a considerable extent, follows this pattern.

Qatar's Constitution guarantees to all individuals the right to access justice (Article 135), and stipulates that "the law shall specify procedures and manner of exercising this right.” However nowadays these procedures and conditions are not inclusive enough for persons with disabilities and do not ensure the full enjoyment of the right access to justice on equal terms. There is, thus, an urgent need to review the procedural law incorporating the principles of CRPD.

The Civil and Commercial Procedure Law (Law 13 of 1990) is applicable whenever there is an absence of other specific legislation. In the text, legal capacity is a prerequisite to becoming a party in judicial proceedings. The general rule is that incapacitated persons act before the courts through their representatives ${ }^{42}$ according to the current substitution system. The system provides safeguards such as the need for express court permission to initiate legal action or to appeal court decisions to higher authorities and to ensure that substitution mechanisms also protect the incapacitated from their representatives. These safeguards are especially strong in the case of victims of crime. ${ }^{43}$ However, as seen above, the substitution mechanism is obsolete in the light of the CRPD, and there are relatively uncomplicated ways for Qatar to move towards the CRPD-advocated supporting model. In this framework, incapacitated plaintiffs would have the chance to have not only their interests protected but also to have their preferences considered and assessed in legal pronouncements.

Persons with psychosocial and intellectual disabilities face legal restrictions to participation as witnesses in judicial proceedings under the current legal framework. Article 263 of the Civil and Commercial Procedure Law includes being "sound of mind" as a requirement to be considered a competent witness. This responds to an all-or-nothing

\footnotetext{
${ }^{41}$ Inclusion Europe, Justice, Rights and Inclusion for People with Intellectual Disability, 2007, pp. 23ff.

${ }^{42}$ Law 13/1990 Civil and Commercial Procedure Law.

${ }^{43}$ Law 223/2004 Regarding Promulgating the Criminal Procedure, Articles 5, 6, and 20 among others.
} 
concept of legal capacity. This notion would need to be reviewed in light of the CRPD's principle of non-discrimination. Such a review would serve not only the interests and preferences of persons with intellectual and psychosocial disabilities but also justice in general, when their testimony is critical for the courts to judge a case.

Article 283 of the Civil and Commercial Procedure Law provides that "in the event of the inability of the witness to speak, he shall testify in writing or by signing if he is capable of making himself understood.” This flexibility is a positive aspect of the current legislation in terms of CRPD compliance. However, it would be even better if there were an interpretive rule clarifying that "in writing" should be considered an example of how persons with communication difficulties could be assisted by other methods, including, but not limited to, assistive mechanisms, intervention of experts, and the provision of support depending on the situation and the needs of the witness. This would enable all persons with disabilities to make themselves understood and give testimony before the courts. This interpretation could be promoted and consolidated in practice by different mechanisms according to Qatar's legal and institutional framework.

To an extent, this extended interpretation has been made in the sphere of criminal proceedings. As the latest report produced by Qatar for the Committee on the Rights of Persons with Disabilities notes “...Article 72 of the Criminal Procedure Law [provides] that, in the case of litigants or witnesses who do not understand Arabic, the public prosecutor must hear their statements through an interpreter... Hence, when questioning deaf or mute persons as either suspects, witnesses or victims, the public prosecutor must employ the services of a sign language interpreter." A clear and ample interpretive clause that extends the notion of "an interpreter" to all assistive methods for persons who cannot communicate could cut across all judicial spheres, since both Law 13/1971 on the System of the Courts of Justice (Article 43) and Law 10/2003 Promulgating the Law on Judicial Authority (Article 16) also refer to the intervention of an interpreter to hear the statements of parties or witnesses who are unable to speak Arabic.

Although we believe that the above-mentioned suggestions would immediately advance access to justice for persons with disabilities, it cannot be ignored that the Committee on the Rights of Persons with Disabilities has expressed concern about the lack of legal aid and assistance and procedural accommodations and programs specifically designed to support persons with disabilities in the justice system. The Committee has recommended that the state train its court staff, judges, police, and prison staff to uphold the rights of persons with disabilities, including the right to a fair trial and the obligation to provide reasonable accommodations. Qatar's courts administration would need to set up the correspondent infrastructure to remove all physical, informational, and communicational barriers. However, assessing such infrastructure falls beyond the scope of our research.

Section 7 of Law 23/2004 Regarding Promulgating Criminal Procedure Code, addressing the issue of "mentally disabled suspects", raises concerns from the CRPD's 
perspective. Article 209 allows the forced placement under observation in a specialized therapeutic facility of a suspect suffering from "mental disability or serious mental illness." According to Article 212, these suspects shall not be subjected to criminal proceedings but shall be placed in a therapeutic facility until their release on the basis of a medical report.

Although the Law on Mental Health regulates the annual review of all placements and establishes that these patients shall possess all rights enjoyed by other "psychiatric patients," this detention implies a special deprivation of liberty on the grounds of disability without determining the suspect's participation in the offense and without the requirements that Qatari legislation itself establishes in the case of precautionary detention. As the Committee on the Rights of Persons with Disabilities noted, according to Qatari legislation, "persons with intellectual and/or psychosocial disabilities accused of an offense are declared unfit to stand trial and not given due process." 44

Provisions in current Qatari legislation regarding “mentally disabled suspects” are incompatible with Articles 5, 14, and 13 of the CRPD and should be reviewed. Persons with psychosocial disabilities suspected of committing a crime should have all the guarantees of due process and should be provided with the necessary support to exercise their right to a defense. The primary response in these cases should be to aim not to deprive individuals of their liberty in therapeutic facilities, but rather to provide them with social and community mechanisms and services to promote their inclusion in the community.

The Committee on the Rights of Persons with disabilities has also expressed its concern about victims of crime with intellectual and/or psychosocial disabilities who may be temporarily placed in therapeutic institutions while their case is being resolved. This measure, which has a protective aim, may not be compliant with the CRPD, given that it implies a deprivation of liberty based on disability. In the CRPD framework, when special measures of protection are needed, the will of the victim should be taken into account and support for the expression of their preferences should be provided.

Although prisoners with disabilities have the same rights as other prisoners in Qatar, there are no legal measures or protocols to ensure the accessibility of facilities, educational programs, and services, or the provision of reasonable accommodations and support. Despite guarantees provided in Qatari legislation, with respect to their ability to seek legal redress and file grievances, those inmates are not guaranteed accessibility to these proceedings. This is also true in relation to the conditions of detention in deportation centers.

\footnotetext{
${ }^{44}$ Concluding Observations. CRPD/C/QAT/CO/1, para. 27.
} 


\subsection{Participation}

Participation in the community is one of the goals of the CRPD, aimed at eliminating all traces of the discredited norm of keeping persons with disabilities hidden in order to protect either them or society from their supposed ill influence.

Participation may be considered from different angles. Firstly, participation is, for the Convention, a means by which all individuals are empowered to make social decisions. Accordingly, public policies and rulings should be developed in coordination with those affected. This participation is usually channeled through social organizations that represent the interests of persons with disabilities. Secondly, in a more traditional understanding, participation refers to the individual's right to political participation. Thirdly, participation is understood as participation in the community.

The Qatari Constitution has a number of provisions that guarantee these different participatory rights. Article 42 guarantees "the right of citizens to vote and to be elected in accordance with the Law." Article 44 articulates "the right of citizens to assemble in public," while Article 45 protects "the right of citizens to establish associations.” Article 47 establishes the right to free speech, the basic tool for political and social participation in public affairs. These general principles are assured through specific legislation on behalf of persons with disabilities.

In effect, Law 2/2004 mandates that the state secures the participation of persons with disabilities in decisions related to their own affairs (Article 2.9) through establishing procedures and guarantees of participation. Article 3, in turn, states that the Supreme Council for Family Affairs shall work to ensure opportunities to participate in sports and entertainment and recognizes the need to develop the abilities of persons with disabilities (Article 3.5) and to provide special services in the fields of care, relief, vocational training, family services, technology, sports and entertainment (Article 3.6). The general and special legal framework set the basic legal rights for participation. However, other pieces of legislation may need to be reviewed.

For example, Decree 17/1998 regarding the election of members of the Central Municipal Council, elections that are regularly held in Qatar, establishes that when voters are unable to mark their ballot, they may communicate their choice orally only to the president of the polling station, who will mark their ballot card and put it in the ballot box. Although this procedure is aimed at guaranteeing the right to vote, it compromises the secret nature of voting. ${ }^{45}$ As the Committee on the Rights of Persons with Disabilities has pointed out, legislative and other measures should guarantee accessibility to ballots, election materials, and polling stations, while voters with disabilities should have the right

\footnotetext{
${ }^{45}$ Ibid. CRPD/C/QAT/CO/1, para. 51.
} 
to choose the person who will assist them in the act of voting. ${ }^{46}$ It should be mentioned that the Supreme Council for Family Affairs established a committee to promote the participation of persons with disabilities in elections. This committee organized a seminar on the subject in 2015, and materials of the National Human Rights Committee (NHRC) on awareness and education of political rights were translated into braille. ${ }^{47}$

How the right to participation translates into effective opportunities to participate is beyond the scope of our study. However, it can be said that currently there is a range of interpretations of the means by which disabled persons can fully participate.

The UN Committee on the Rights of Persons with Disabilities pointed out that in the past there was a lack of consultation with both individuals with disabilities and with independent organizations regarding disability-related policies and the process of implementation of the CRPD. ${ }^{48}$ The 2010 Special Rapporteur mentioned that what was required was the "establishment of a federation of all civil society organizations of persons with disabilities in Qatar." 49 Along these lines, the NHRC's 2014 Report on the situation of Human Rights in the State of Qatar remarked that "Qatar does not have specialized associations for certain types of mental disabilities such as autism, mental paralysis, Down's syndrome, and others, unlike the neighboring countries, which have such associations." 50

Regarding the right to freedom of expression and opinion, and access to information, the Committee on the Rights of Persons with Disabilities urged the recognition and promotion of the use of Qatari sign language "to ensure the involvement of and consultation with the Qatari deaf community in the formulation, implementation, and monitoring of all sign language policies, projects, and activities of the State party at the

46 General Comment No. 2 on Accessibility, May 22, 2014, CRPD/C/GC/2. Available at http://tbinternet.ohchr.org/_layouts/treatybodyexternal/Download.aspx?symbolno=CRPD/C/GC/2\&Lang=en (last accessed April 1, 2017). In particular the Committee recommended Qatar improve these aspects, Concluding Observations. CRPD/C/QAT/CO/1, para. 52.

47 See the report on the NHRC and the Qatar Social and Cultural Center for the Blind's seminar on the political rights of persons with disabilities (April 2015). Available at http://www.nhrc-qa.org/en/the-nhrc-andqatar-social-and-cultural-center-for-the-blind-held-a-seminar-on-the-political-rights-of-persons-with-

disabilities/ (last accessed January 3, 2017). A report of the NHRC working group on monitoring the elections of the Central Municipality Council in 2015 concluded with some recommendations (included in the 2015 NHRC Report on the Situation of Human Rights in the State of Qatar, cit., p. 41).

${ }^{48}$ Concluding Observations. CRPD/C/QAT/CO/1, para. 9.

${ }^{49}$ UN Special Rapporteur on Disability Shuaib Chalklen, Mission to Qatar (March 9-13, 2010) Preliminary Observations, p. 2. Available at www.un.org/disabilities/documents/specialrapporteur/qatar_2010.doc (last accessed January 3, 2017).

${ }^{50}$ NHRC, Report of the National Human Rights Committee on the Situation of Human Rights in the State of Qatar 2014, cit., p. 50. The 2015 NHRC Report on the Situation of Human Rights in the State of Qatar, cit., p. 75 also pointed out the "lacking of sufficient number of civil society organizations that concerns with disability issues”. The CRPD Committee also expressed its concern about the lack of diversity in the range of independent organizations with disabilities, Concluding Observations. CRPD/C/QAT/CO/1, para. 9. 
national and regional levels." ${ }^{51}$ Although some improvements are needed, key informants have reported to our team that the deaf community in Qatar is working hard to promote Qatari sign language.

With respect to the right to participate in cultural life, some inclusive initiatives have already been developed in specific areas such as sports, ${ }^{52}$ but major efforts are necessary in other areas. Qatar's ratification of the Marrakesh Treaty to Facilitate Access to Published Works for Persons who are Blind, Visually Impaired, or Otherwise Print Disabled, should enable blind persons and persons with disabilities to access printed materials. $^{53}$

\subsection{Audiovisual accessibility}

Accessibility, in general, is the main axis around which the rights of persons with disabilities revolve. Accessibility overcomes discrimination and is an indispensable means of achieving the effective participation of persons with disabilities in the community. Highlighting its importance, the role of universal accessibility is recognized in the preamble to the CRPD "in enabling persons with disabilities to fully enjoy all human rights and fundamental freedoms." It is also included in the general principles of Article 3.

Article 9 of the CRPD is entirely dedicated to this principle: "To enable persons with disabilities to live independently and participate fully in all aspects of life, States Parties shall take appropriate measures to ensure to persons with disabilities access, on an equal basis with others, to the physical environment, to transportation, to information and communications, including information and communications technologies and systems, and to other facilities and services open or provided to the public, both in urban and in rural areas."

Throughout the Convention, universal accessibility is justified by reference to three other rights: independent living, participation in social life, and equal opportunities. ${ }^{54}$

Two different means of achieving accessibility are usually highlighted: universal design and reasonable accommodation. A comprehensive sense of accessibility involves: (i) universal design, which functions as a general principle; (ii) accessibility measures, which appear when universal design is not satisfied; (iii) reasonable accommodations, which arise when accessibility is not universal. Discrimination arises if possible and reasonable accessibility is not universal.

\footnotetext{
${ }^{51}$ Concluding Observations. CRPD/C/QAT/CO/1, para. 40.

52 Ibid., CRPD/C/QAT/1, paras 214-216.

53 Ibid., CRPD/C/QAT/CO/1, paras 53 and 54.

54 This point of view is also assumed by the Committee on the Rights of Persons with Disabilities in the General Comment No. 2 on “Accessibility”, Ibid., CRPD/C/GC/2, adopted April 11, 2014.
} 
The CRPD includes universal accessibility to buildings, roads, transportation, and other physical facilities (schools, hospitals, workplaces) as particular requirements in its accessibility stipulations. It also includes access to information services, communications, and electronic services, fields of singular relevance given that they are critical for the articulation of many other rights, most particularly in this era of information technologies. In light of the CRPD, there is an obligation on the part of both state authorities and the private sector to ensure accessibility to persons with disabilities. Communication access opens the door to information, opinion-building, education, leisure, and culture.

Although, as noted previously, the Committee on the Rights of Persons with Disabilities Qatar does not have a general framework to ensure accessibility for persons with disabilities, on an equal basis with others, to all facilities and services open to or provided for the public, ${ }^{55}$ Qatari legislation on information technology and communications is quite progressive regarding persons with disabilities. The sectorial legislation and most recent policies appear updated.

The Ministry of Transport and Communications (previously called the Ministry of Information and Communications Technology) has different strategies that are designed to promote the rights of persons with disabilities and has created important institutions in this field. ${ }^{56}$

According to Article 3 of Law 36/2004 on the Establishment of the Supreme Council for Communication and Information Technology (ictQatar), the Council's mission is to regulate both the communications sector and information technology in general. In September 2011, the Council adopted Qatar's eAccessibility Policy. According to this rule, accessibility and inclusion should be pursued for persons with disabilities, and the elderly, identifying a number of barriers in the field of information technologies.

On the other hand, in June 2010, with the participation of Ooredoo, the national telecom provider, along with Vodafone Qatar, Qatar National Bank, and Microsoft, ictQatar created the Qatar Assistive Technology Center (MADA), ${ }^{57}$ a public-private nonprofit center for assistive technology. MADA's aim is to connect persons with disabilities to the world of information and communication, increasing their opportunities through innovation and by promoting new and trusted technologies and services. MADA's operational strategy is based on three pillars-Education, Employment and Communityand its work has become a point of reference in Arab region.

\footnotetext{
${ }^{55}$ Concluding Observations. CRPD/C/QAT/CO/1, para. 19.

56 Such as the Digital Strategy, which aims at facilitating everyone's access to basic technologies, and at providing the skills needed to use certain technology. See the Ministry of Transport and Communication's Digital Inclusion strategy, available at http:/www.ictqatar.qa/en/digital-society/digital-inclusion (last accessed 31 March, 2017).

${ }^{57}$ For further details, see https://mada.org.qa/en/Pages/default.aspx.
} 
The Communications Regulatory Authority ${ }^{58}$ (CRA), created in 2014 and tasked with ensuring competition and consumer protection in the telecom market, developed the Telecommunications Consumer Protection Policy (January 2014) and the Code on Advertising, Marketing, and Branding (September 2014).

Qatar's e-Accessibility Policy places a range of obligations on service providers in relation to services for persons with disabilities including the provision of accessible handsets and user interfaces, an accessible public payphone service, accessible telecommunications services, and accessible emergency services. Meanwhile, the CRA's Code on Advertising, Marketing, and Branding, aimed at regulating advertisements and promotions of products and services, also includes some rules for the protection of vulnerable consumers and consumers with special needs.

Audiovisual accessibility is at the vanguard of compliance with the mandates of the CRPD, although some minor-but conceptually important-adjustments could be recommended. One is the use of the language of rights and human rights, as promoted by the CRPD. The other is that the different agencies working in the sector may face coordination issues due to their varied natures and structures. Last, but not least, the rules are clear, but the e-Accessibility Policy is not binding and there is no precise schedule of penalties in cases of infraction.

\section{Conclusions}

This section aims to present some conclusions related to the fields explored in the previous pages, together with some recommendations on general changes required to Qatari law for a clear, durable and unquestionable implementation of the CRPD.

Regarding Qatar's general approach towards disability, the main conclusions are:

1. The key challenge faced by Qatar in order to implement the CRPD is to introduce the social model and the human rights-based approach to disability replacing the medical model, the point of view of assistencialism and the strategy of specialized solutions.

2. Full compliance with the CRPD requires a new law on disability, adapting the principles of the Convention to the Qatari context and introducing the required changes into Qatar's general rules. This law should assume a social definition of disability; introduce an explicit prohibition of discrimination on the grounds of disability; incorporate the key concepts of the CRPD (regarding accessibility, universal design, reasonable accommodations, and independent living) and promote participation and full inclusion in society for persons with disabilities.

\footnotetext{
${ }^{58}$ See their website at http://cra.gov.qa/en
} 
3. Until the approval of this law Qatari legislation may be reinterpreted in the light of the new paradigm, the principles, and the key concepts of the CRPD in order to ensure a high standard of protection for the rights of persons with disabilities in the country.

In relation to Qatar's private law, it is possible to conclude:

1. Qatari law allows the deprivation of legal capacity based on a lack of "mental faculties" and establishes a substitution system in the decision-making process. The special Law 2/2004 regulating this issue is the same as that applied in the case of minors, and the guiding principle is ensuring the best protection of the persons, without taking into account their personal will and preferences.

2. Hence, legal reform is required to recognize: the full legal capacity of persons with disabilities on equal terms with others, their right to make their own decisions in all areas of life, and the obligation of the State to take into account their will and preferences. Qatar should implement a system to support decision-making and to promote the autonomy of persons with disabilities and the exercise of their rights.

3. There are some mechanisms that could allow persons under guardianship to make certain decisions and some assistance measures have also already been established. These points imply an advantage over other national legislations and could be expanded to approximate in practice Qatar's compliance with the Convention, pending the necessary legal reforms.

These are the main conclusions related to health:

1. The approach to disability in Qatar adopts the perspective of the medical model, so disability is understood to be a medical problem, Health is a field with a considerable impact on the whole life of a person with disabilities in Qatar. The adoption of the social model of disability will change this situation.

2. Qatari law ensures persons with disabilities are given free access to healthcare, but it does not ensure that some of them (in particular persons with psychosocial or intellectual disability, especially if they are legal incapacitated persons) are able to make their own decisions about their treatment. Perhaps one way to ensure this right would be to adopt a procedure similar to that employed in the case of a need for an interpreter, shifting the current representation model to an "assistance in taking decisions" model. Guarantees provided by the Policy on the Care of [the] Vulnerable Patient Population CL 7221 must be applied to patients with intellectual disabilities, and measures delivering assistance in the taking of decisions should be incorporated into the legal paradigm, protecting the rights of persons with disabilities. 
3. Qatar's National Mental Health Strategy 2013-2018 is the major tool employed to promote social inclusion of persons with psychosocial disability, focusing on the fight against stigma and the provision of community services. The new Law on Mental Health is aimed at improving guaranteed rights of the patients, but it establishes provisions regarding involuntary hospitalization that, although similar to other national legislations, do not comply with the standards of the CRPD and should be reviewed.

The main conclusions in the field of education are:

1. Qatar is facing a paradigm shift to a more inclusive model. However, some children with disabilities may remain outside of the educational system, and special education seems to be the chosen route for persons with intellectual disabilities. A more effective change to the model on the basis of an inclusive education is needed.

2. It is also important to clarify the educational curriculum from the point of view of diversity, ensuring continuity for persons coming from special systems, providing persons with disabilities the tools needed for vocational training, and enabling them to achieve the highest levels of education, if that is their choice.

From the arguments previously noted, the conclusions regarding the labor market are:

1. Qatari regulations on the right to work of persons with disabilities are anchored in the medical model. The social model should also be adopted in this field.

2. Regulation of disability from specialty is a technical problem because the requirements of the Law in Respect of People with Special Needs remain isolated from general employment regulation. As a result, the structure that governs access to work seems to separate rather than include persons with disabilities as required as a central premise of the Convention. Measures determining labor rules for persons with disabilities must be linked to general labor rules.

In relation to access to justice, these are the most relevant conclusions:

1. Qatar’s justice system does not ensure equal access for persons with disabilities.

2. Despite some current provisions designed to protect persons with disabilities and that could be used to promote their participation in judicial proceedings, the effectiveness of the right to access justice in the context of disability requires the following: recognizing the capacity of all persons with disabilities to participate; ensuring full accessibility of the justice system; providing procedural accommodations and supports; and implementing training programs to make professionals in the sector aware of the rights of persons with disabilities and ensuring they are able to communicate effectively with persons with disabilities. 
On participation, we conclude:

1. Measures present in rules regarding elections for the Central Municipal Council are not enough to guarantee the political participation of persons with disabilities in Qatar. Major efforts should also be made to ensure the rights of persons with disabilities to participate in cultural life, their right to freedom of expression and opinion, and their right to access information.

2. Qatar must involve persons with disabilities in the process of implementing the Convention. Its support to promote the creation of civil society organizations in the field of disability is required.

Finally, our conclusions on audiovisual accessibility are:

1. Although Qatar should adopt legislation to ensure barrier-free public facilities and services, develop a comprehensive accessibility plan and justify accessibility obligations from the point of view of the human rights, some good initiatives regarding the audiovisual area have been identified.

2. However the current measures on audiovisual accessibility should also adopt the language of human rights. Other necessary improvements in this domain are securing a better coordination between different agencies and the establishment of binding obligations with enforceable and effective sanctions for non-compliance.

After the previous reflections, we can conclude that disability is a clear subject of concern in Qatar, but also that there is still a long way to go in order to realize full compliance with the CRPD. As we explained above, the implementation of the CRPD in Qatar requires reforms in the general framework of disability and in several sectoral legislations, although some changes may be advanced through a reinterpretation of current law.

In any case, to ensure successful CRPD implementation, Qatar should adopt some additional measures:

1. Create an institution responsible for leading disability policy and guaranteeing that measures are rooted in the principles of the CRPD and the social model.

2. Promote, strengthen, and empower associations representing the interests of persons with disabilities. This is to ensure that public decisions on persons with disabilities are created with their participation, in compliance with the framework of the CRPD.

3. Modify the social perception of disability and provide specific training to agents in all fields in which the CRPD is relevant. The training of legal professionals, who have to make effective the rights of the persons with disability, is urgent. 


\section{REFERENCES}

Al Attiyah A. and Mian M. (2009). "Disability in the State of Qatar”, in Marshall C.A. et al. (eds), Disabilities. Insights from Across Fields and Around the World, vol. 3 "Responses: Practices, Legal, and Political Frameworks”, Praeger, Westport.

Ortoleva S. (2011). "Inaccessible Justice: Human Rights, Persons with Disabilities and the Legal System”, LSA Journal of International \& Comparative Law, vol. 17:2.

Quinn G. (2009). “An Ideas Paper on Legal Capacity”, Disability, European Foundation Center, Brussels. Available at http://www.inclusionireland.ie/sites/default/files/attach/basicpage/846/anideaspaperbygerardquinnjune2009.pdf (last accessed March 29, 2017).

Sharkey T. (2017., “Mental Health Strategy and Impact Evaluation in Qatar”, Bjpsych International, Volume 14, Number 1, February.

Snoj J. (2013). “Population of Qatar by Nationality”, BQ Magazine. Business in Qatar and Beyond, December 18. Available at http://www.bqmagazine.com/economy/2013/12/population-qatar (last accessed May 31, 2016). 